\title{
APAKAH KEPERCAYAAN MUWAKIF DITENTUKAN OLEH AKUNTABILITAS PENGELOLAAN WAKAF TUNAI DAN PERAN NADZIR?
}

\author{
Agus Sulaeman, Ai Nur Bayinah, Roni Hidayat \\ Sekolah Tinggi Ekonomi Islam SEBI
}

Email:agus.27s.akun@gmail.com,ai.nur.bayinah@sebi.ac.id,ronihidayat.ma@gmail.com

\begin{abstract}
This study aims to analyze the influence of accountability in cash waqf management and role of nadzir towards level of muwakif trust in Indonesia. This research type is quantitative research using a survey method with the correlation approach. The data used are primary data by spreading the questionnaires to 100 muwakif in Indonesia. samples were taken by using random sampling techniques. Analysis data used to test the hypotheses using multiple linear regression analysis. The results of this study stated that the variable of accountability in cash waqf management and role of nadzir have a positive effect and significant on the level of muwakif trust in Indonesia, Therefore to increase the muwakif trust, nadzir institutions must increase information dissemination, honesty, punctuality, according to ethical standards and laws, clear targets, and easy access to information. Also, the role of nadzir in carrying out their duties must be increased, like the responsibility for collecting and managing cash waqf, the efficiency of the program and the budget, the rationalization between the draft budget and the program to be implemented.
\end{abstract}

Keywords: Accountability; Cash Waqf Management, Role of Nadzir, Muwakif Trust

\section{ABSTRAK}

Penelitian ini bertujuan untuk menganalisis pengaruh akuntabilitas dalam pengelolaan wakaf tunai dan peran nadzir terhadap tingkat kepercayaan muwakif di Indonesia. Jenis penelitian ini adalah penelitian kuantitatif dengan menggunakan metode survei dengan pendekatan korelasional. Data yang digunakan adalah data primer dengan menyebarkan kuisioner ke 100 muwakif di Indonesia. Sampel diambil dengan menggunakan teknik random sampling. Analisis data digunakan untuk menguji hipotesis menggunakan analisis regresi linier berganda. Hasil penelitian ini menyatakan bahwa variabel akuntabilitas dalam pengelolaan wakaf tunai dan peran nadzir berpengaruh positif dan signifikan terhadap tingkat kepercayaan muwakif di Indonesia, oleh karena itu untuk meningkatkan kepercayaan muwakif, lembaga nadzir harus meningkatkan penyebaran informasi, kejujuran, ketepatan waktu, sesuai dengan standar dan hukum etika, target yang jelas, dan akses mudah ke informasi. Juga, peran nadzir dalam melaksanakan tugas mereka harus ditingkatkan, seperti tanggung jawab untuk mengumpulkan dan mengelola wakaf tunai, efisiensi program dan anggaran, rasionalisasi antara rancangan anggaran dan program yang akan dilaksanakan

\section{Kata kunci: Akuntabilitas; Manajemen Wakaf Tunai, Peran Nadzir,} Kepercayaan Muwakif 


\section{PENDAHULUAN}

Dalam perekonomian yang diatur oleh Islam, terdapat beberapa kegiatan yang memliliki tujuan untuk kepentingan sosial antara lain zakat, infaq, shadaqah, dan wakaf. Zakat, infaq, dan shadaqah merupakan kegiatan yang paling sering dilakukan, dimana dalam pengelolaannya pun tidak terlalu sulit, sehingga banyak lembaga sosial yang mengelola kegiatan tersebut. Sedangkan di luar itu yakni wakaf sedikit berbeda dalam pengelolaan dan penghimpunannya, pada umumnya wakaf dikenal sebagai merelakan tanah yang dimiliki untuk tujuan umum seperti pembangunan masjid dan sekolah. Hal ini menjadi salah satu faktor yang membuat masyarakat pada umumnya terutama masyarakat yang memiliki penghasilan dibawah rata-rata belum tertarik dengan wakaf, dikarenakan mereka berpikir bahwa untuk melakukan wakaf perlu biaya yang sangat tinggi dibandingkan zakat, infaq, dan shadaqah.

Pada dasarnya, fenomena admisitrasi wakaf yang tidak efisien di negara-negara muslim dapat dikaitkan dengan kolonialisme dari tanah muslim (Yaacob, 2013), situasi politik dan kurangnya akuntabilitas mutawalli. Ada bermacam-macam variasi yang berkaitan dengan pengembangan wakaf di berbagai daerah disebabkan kondisi politik, ekonomi dan budaya lokal. Namun, dalam dekade terakhir kesadaran revitalisasi lembaga wakaf baru muncul di antara negara-negara Muslim. Misalnya, pemerintah Sri Lanka, Sudan, dan Indonesia yang menyadari kebutuhan akan perkembangan wakaf dapat menciptakan masyarakat yang lebih baik, dalam artian menjadikan masyarakat menjadi lebih sejahtera. diantara negara-negara muslim, pemerintah Indonesia telah membuat reformasi besar dalam revitalisasi lembaga wakaf melalui penerapan tindakan wakaf untuk mengatur lembaga wakaf di Indonesia, hal ini tertuang dalam UU No.41 tahun 2004 mengenai wakaf (Pitchay \& Abd Jalil, 2016).

Berkembangnya lembaga wakaf di Indonesia pun menunjukkan antusiasme masyarakat mengenai wakaf. Tidak sedikit masyarakat yang telah sadar dalam mengelola uang mereka untuk kegiatan amal dengan menginvestasikan uang mereka dalam kegiatan perwakafan di Indonesia pada lembaga-lembaga wakaf di Indonesia. Kepercayaan yang besar dari para masyarakat kepada lembaga wakaf, menjadikan lembaga wakaf menjadi salah satu hal yang perlu diperhatikan dalam penelitian ini. Sebagai seorang pewakaf, sudah menjadi hak seorang pewakaf untuk mengetahui bagaimana penggunaan harta mereka yang telah diwakafkan oleh lembaga tersebut (Ihsan, Septriani, \& Eliyanora, 2016).

Penelitian sebelumnya mengenai akuntabilitas lembaga pengelola wakaf Telah dilakukan oleh Budiman yang melakukan penelitian Tentang akuntansi lembaga pengelola wakaf . Hasil penelitian budiman menyatakan bahwa penerapan prinsip akuntabilitas telah meningkatkan kepercayaan publik terhadap lembaga pengelola wakaf (Budiman, 2011). Akuntabilitas merupakan proses dimana suatu lembaga menganggap dirinya bertanggung jawab secara terbuka mengenai apa yang dilakukan dan tidak dilakukannya. 
Secara operasional akuntabilitas diwujudkan dalam bentuk pelaporan (reporting), pelibatan (involving), dan cepat tanggap (responding). Akuntabilitas dapat menumbuhkan kepercayaan (trust) masyarakat kepada lembaga. Karena itu akuntabilitas menjadi sesuatu yang penting karena akan mempengaruhi legitimasi terhadap lembaga pengelola wakaf. Dengan demikian, akuntabilitas bukan semata-mata berhubungan dengan pelaporan keuangan dan program yang dibuat, melainkan berkaitan pula dengan persoalan legitimasi publik (Budiman, 2011).

Salah satu kunci keberhasilan wakaf adalah terletak pada eksistensi pengelola, oleh karena itu nadzir memiliki peranan yang sangat penting bagi pengelolaan wakaf (Kasdi, 2014). Dengan demikian, nadzir seharusnya di dukung dan didorong semaksimal mungkin untuk mencapai level kinerja Dan performa yang maksimal, sehingga lebih signifikan dalam memainkan peran sosial untuk meningkatkan peran wakaf. Pengelolaan wakaf yang dilakukan oleh nadzir secara baik dan profesional akan membuat Masyarakat akan semakin percaya sehingga jumlah muwakif akan terus semakin bertambah banyak.

Masalah yang lagi dihadapi para nadzir sekarang ini adalah faktor Trust dari masyarakat terhadap lembaga pengelola wakaf tunai, dan aspek sistem yang minim kreativitas dalam mengelola dan mengembangkan dana wakaf yang menganggur. Sehingga pengelolaan lembaga pengelola wakaf (nadzir) terlihat seperti hidup segan mati tak mau. Hasilnya adalah harta wakaf nya dikelola asal jalan dan masih kurang produktif (Dahlan, 2018).

Faktor yang mempengaruhi kepercayaan dari masyarakat, yaitu: pertama, masalah sosialisasi, salah satu mazhab yang populer di Indonesia adalah Mazhab Syafi'I, di mana ini tidak menerangkan tentang wakaf uang. Hal ini merupakan tantangan karena masyarakat akan mengalami konflik dengan adanya pemahaman yang dianggap baru di kalangannya. Tak hanya terjadi pada masyarakat saja, masalah sosialisasi juga terhambat pada media, baik media cetak dan elektronik. Sosialisasi dan edukasi mengenai wakaf belum terlihat masif. Hal inilah yang menyebabkan masalah wakaf uang tidak familiar di kalangan masyarakat, terutama masyarakat pedesaan. Kedua, masalah kelembagaan yang masih belum terlalu kuat payung hukumnya. Ketiga, kurangnya kepekaan pemerintah untuk memanfaatkan potensi wakaf uang sehingga akses masyarakat untuk menyalurkan wakafnya masih belum dijangkau secara optimal serta transparan dalam pengelolaan dan alokasi dana wakaf masih kurang sehingga hal ini dapat menurunkan kepercayaan masyarakat untuk menyalurkan wakaf (Fitri \& Wilantoro, 2018).

Berdasarkan uraian latar belakang masalah, maka tujuan penelitian ini adalah untuk mengetahui pengaruh akuntabilitas pengelolaan wakaf tunai dan peran nadzir baik secara simultan maupun parsial terhadap tingkat kepercayaan muwakif di Indonesia. 


\section{TELAAH TEORITIS DAN PENGEMBANGAN HIPOTESIS}

\subsection{WAKAF TUNAI}

Wakaf tunai merupakan wakaf yang dilakukan individu, kelompok, dan lembaga atau badan hukum dalam bentuk uang tunai, termasuk dalam pengertian uang adalah surat-surat berharga, seperti saham, cek, dan lainnya yang disalurkan dan digunakan hanya untuk hal-hal di perbolehkan oleh syariat Islam. Hukum wakaf tunai telah menjadi perhatian para ahli fikih. Beberapa sumber menyatakan bahwa wakaf uang telah dipraktikan oleh masyarakat yang menganut mazhab Hanafi (Santoso, 2017).

\subsection{PENGERTIAN DAN URGENSI AKUNTABILITAS}

Literatur-literatur yang ada menunjukkan ada dua ide dasar yang membangun konsep akuntabilitas. Pertama, akuntabilitas sangat berkaitan erat dengan responsibilitas atau tanggung jawab. Banyak peneliti yang kemudian setuju bahwa akuntabilitas lahir karena adanya keinginan untuk menerima dan menunjukkan tanggung jawab. Konsep yang kedua adalah akuntabilitas akan melibatkan setidaknya dua pihak, pihak yang memberikan responsibilitas dan satunya lagi pihak yang menerima responsibilitas itu dengan kesanggupan untuk melaporkan, memperhitungkan atau memberikan penjelasan atasnya (Ihsan et al., 2016). Akuntabilitas adalah kesanggupan untuk menunjukkan tanggung jawab oleh pihak yang menerimanya dengan kewajiban untuk melaporkan, memperhitungkan dan memberikan penjelasan atas tanggung jawab yang diserahkan padanya.

Akuntabilitas telah menjadi fenomena yang luas yang bisa ditemui dalam hampir setiap aspek kehidupan manusia, mulai dari kehidupan pribadi, sosial, dunia kerja dan juga dalam ajaran agama. Tanpa akuntabilitas, maka seseorang atau lembaga akan kehilangan kepercayaan dari masyarakat. Dari perspektif agama dapat di garis bawahi bahwa konsep akuntabilitas adalah tema sentral dalam ajaran Islam, karena akuntabilitas kepada Allah dan juga komunitas muslim merupakan bentuk nyata keimanan seseorang (Ihsan \& Ibrahim, 2011). Dalam hal ini bentuk akuntansi dalam islam ada dua yaitu Manusia bertanggung jawab kepada Allah dan melakukan pertanggung jawaban kepada sesama manusia atas apapun kontrak yang telah mereka buat. Ilmu Akuntansi dan pelaporan merupakan sebuah dasar yang dianggap sebagai salah satu perangkat yang paling penting bagi akuntabilitas (Yaacob, Petra, Sumardi, \& Nahar, 2015).

\subsection{NADZIR}

Nadzir merupaka lembaga atau individu yang memiliki peranan paling vital atas pengelolaan dan penghimpunan dana wakaf, sekaligus yang paling bertanggung jawab atas harta wakaf yang dipercayakan padanya, baik menyangkut pemeliharaan harta wakaf, maupun terhadap hasil dan upayaupaya pengembangannya. Semua aktivitas nadzir atas harta wakaf yang dihimpun harus selalu mempertimbangakn agar harta wakaf tersebut berkesinambungan dalam mengalirkan manfaatnya untuk kepentingan 
mauquf 'alaih. Oleh karena itu, peran nadzir bukan berfokus pada masalah menghimpun dana lalu langsung membelanjakannya, akan tetapi bisa menjadikan harta tersebut menjadi aset terlebih dahulu, kemudian mengelola aset tersebut menjadi produktif dan bisa menghasilkan keuntungan agar bisa dimanfaatkan untuk kepentingan lain seperti sedekah. Kemampuan nadzir seperti ini sangat diperlukan agar wakaf bisa lebih maksimal dalam pemanfaatannya, tentu ini menjadi tuntutan nadzir bukan hanya sebatas wawasan tentang wakaf, tetapi memerlukan keahlian agar para nadzir mampu mengelola aset dengan prinsip syariah dalam berinvestasi (Tiswarni, 2014).

Menjadikan aset wakaf menjadi produktif adalah merupakan salah satu tugas dan fungsi nadzir sebagai pengelola. Karena mengelola aset wakaf secara lebih efektif dan efisien adalah merupakan keharusan nadzir dalam menjalankan aktivitasnya (Bayinah, 2012). Dengan dilakukannya pengelolaan wakaf secara profesional oleh nadzir akan memberikan kesempatan pada lembaga wakaf menerapkan prinsip modern dalam pengelolaan wakaf, sehingga membuat performa nadzir lebih baik lagi dalam melakukan kinerjanya (Kasdi, 2014).

\subsection{TINGKAT KEPERCAYAAN}

Kepercayaan pada hakekatnya adalah suatu keadaan psikologis seseorang dalam melakukan aktivitas, dalam hal ini kepercayaan yang dimaksud ketika melakukan wakaf tunai di lembaga nadzir. Dalam wakaf tunai salah satu hal yang memberikan dukungan dalam penghimpunan dan pengembangannya yaitu kepercayaan. Selain itu, kepercayaan juga memberikan indikasi bahwa seseorang ada keinginan untuk bertumpu kepada pihak lain dimana seseorang memiliki keyakinan terhadap pihak tersebut (Sugara \& Dewantara, 2017). Kepercayaan juga merupakan keadaan mental yang didasari oleh keadaan seseorang dan konteks sosialnya, dalam penelitian ini kepercayaan yang diberikan muwakif kepada nadzir.

Dalam definisi lain, kepercayaan di artikan sebagai wujud keyakinan satu pihak terhadap janji pihak lain yang bersifat realible, Dan merupakan alasan dasar untuk memiliki ikatan dengan pihak lain (Elrado H, Kumadji, \& Yulianto, 2014). Beberapa faktor yang menjadi dasar agar terciptanya hubungan yang baik berdasarkan kepercayaan, yaitu :

1. Penilaian terhadap kompetensi atau keandalan perusahaan (perceived competence)

2. Penilaian terhadap keadilan dan kejujuran (perceived fairness)

3. Kepercayaan merupakan bentuk kesediaan satu pihak untuk bergantung pada pihak lainnya (Jasfar, 2012).

\section{METODE PENELITIAN}

Metode penelitian yang digunakan dalam penelitian ini adalah metode survei dengan pendekatan korelasi., teknik pengambilan sampel pada umumnya 
dilakukan secara random (simple random sampling), kemudian dalam pengumpulan data menggunakan instrument penelitian serta analisis data bersifat kuantitatif/statistik, dan bertujuan untuk menguji hipotesis yang telah ditentukan (Sugiyono, 2009).

Populasi yang digunakan dalam penelitian ini yaitu seluruh mustahik yang berwakaf dilembaga nadzir yang ada di Indonesia dan tersertifikasi di BWI. Teknik pengambilan sampel yang digunakan dalam penelitian ini adalah random sampling yaitu pengambilan sampel dengan memberi kesempatan yang sama pada setiap elemen tanpa memperhatikan strata yang ada dalam populasi untuk dipilih menjadi sampel (Sugiyono, 2009).

Analisis data dilakukan dengan menggunakan bantuan program SPSS for Windows 25.00. Kegiatan dalam analisis data adalah mengelompokan data berdasarkan variabel dan jenis responden, menyajikan data tiap variabel yang diteliti, melakukan perhitungan untuk menjawab rumusan masalah dan melakukan perhitungan untuk menguji hipotesis yang telah diajukan.

\section{HASIL DAN PEMBAHASAN}

\subsection{DESKRIPSI RESPONDEN}

Berdasarkan data yang diolah berhasil dikumpulkan dalam penelitian ini melalui kuisioner secara random, dan berdasarkan rumus slovin maka responden yang digunakan adalah sebanyak 100 responden. Karakteristik yang digunakan dalam penelitian ini adalah asal daerah, dan lembaga nadzir yang dipilih oleh muwakif serta nominal yang diwakafkan. Berikut ini merupakan hasil pengelompokan responden berdasarkan kuisioner yang telah dibagikan :

\subsubsection{Deskripsi Responden Berdasarkan Asal daerah}

Pengelompokan responden berdasarkan Asal daerah adalah sebagai berikut:

Grafik 1. Asal Daerah

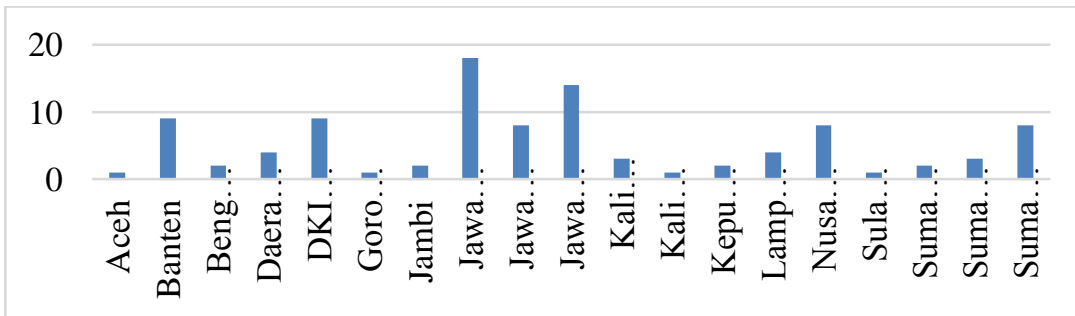

Sumber: Data diolah, 2019

Berdasarkan grafik 1 di atas, dapat diketahui bahwa asal daerah responden sebagian besar adalah di provinsi Jawa Barat sebanyak 18 orang atau $18 \%$, Aceh sebanyak 1 orang atau $1 \%$, Banten 9 orang atau 9\%, Bengkulu 2 orang atau 2\%, Daerah Istimewa Yogyakarta 4 orang atau 4\%, 
Dki Jakarta 9 orang atau 9\%, Gorontalo 1 orang atau 1\%, jambi 2 orang atau $2 \%$, Jawa tengah 8 orang atau 8\%, Jawa Timur, 14 orang atau 14\%, Kalimantan Barat 3 orang atau 3\%, Kalimantan Selatan 1 orang atau 1\%, Kepulauan Riau 2 orang 2\%, Lampung 4 orang atau 4\%, Nusa Tenggara Barat 8 orang atau $8 \%$, Sulawesi Tenggara 1 orang atau 1\%, Sumatera Barat 2 orang atau 2\%, Sumatera Selatan 3 orang atau 3\%, dan Sumatera Utara 8 orang atau $8 \%$. Dapat dikatakan bahwa, responden yang berasal dari daerah Jawa barat lebih tertarik untuk melakukan wakaf tunai.

\subsubsection{Deskripsi Responden Berdasarkan Lembaga Nadzir yang Dipilih}

Pembagian responden berdasarkan lembaga nadzir yang dipilih :

Grafik 2. Lembaga Nadzir

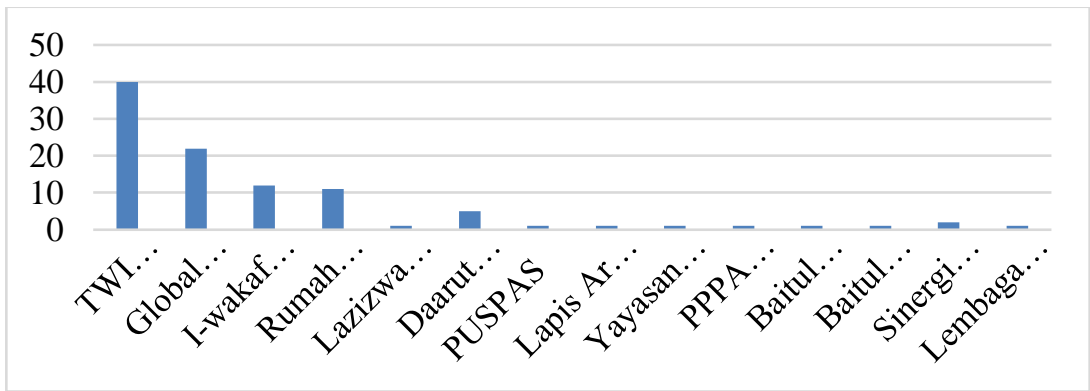

Sumber: Data diolah, 2019

Berdasarkan grafik 2 di atas, dapat diketahui bahwa lembaga nadzir yang paling banyak dipilih oleh responden adalah TWI (Dompet Dhuafa) sebanyak 40 orang atau 40\%, sedangkan Global wakaf (ACT) 22 orang atau $22 \%$, I-wakaf (PKPU) sebanyak 12 orang atau 12\%, Rumah Wakaf indonesia sebanyak 11 orang atau 11\%, Lazizwa Masa sebanyak 1 orang atau $1 \%$, Daarut Tauhid sebanyak 5 orang atau 5\%, PUSPAS sebanyak 1 orang atau $1 \%$, Lapis Ar-Risalah sebanyak 1 orang atau 1\%, Yayasan Nurul hayat sebanyak 1 orang atau 1\%, PPPA DARUL QUR'AN sebanyak 1 orang atau 1 $\%$, Baitul Maal Munzalan indonesia sebanyak 1 orang atau 1\%, Baitul Maal Hidayatullah sebanyak 1 orang atau 1\%, Sinergi Foundation sebanyak 2 orang atau 2\%, dan terakhir Lembaga Wakaf dan pertanahan NU sebanyak 1 orang atau $1 \%$.

\subsection{UJI INSTRUMEN PENELITIAN}

\subsubsection{Uji Validitas}

Uji validitas digunakan untuk menguji valid atau tidaknya suatu kuisioner. Kriteria yang digunakan yaitu jika $r$ hitung lebih besar dari $r$ tabel ( $r$ hitung $>$ $\mathrm{r}$ tabel), maka data dikatakan valid. Tingkat signifikannya yaitu 5\% atau 0,05 . Rumus perhitungan Degree of freedom yaitu, dimana $n$ adalah jumlah sampel dan k adalah jumlah konstruksi. Dalam penelitian ini jumlah sampel yaitu 100, yaitu dengan menggunakan alpha 0,05 atau 5\%, maka didapat $r$ tabel sebesar 0,195. Adapun untuk hasil uji validitas adalah sebagai berikut: 
Tabel 1. Uji Validitas

\begin{tabular}{|c|c|c|c|c|}
\hline Variabel & Pertanyaan & r Hitung & r Tabel & Keterangan \\
\hline \multirow{6}{*}{$\begin{array}{l}\text { Akuntabilitas pengelolaan wakaf tunai } \\
\text { (X1) }\end{array}$} & $\mathrm{X1.1}$ & 0,550 & 0,195 & Valid \\
\hline & $\mathrm{X} 1.2$ & 0,604 & 0,195 & Valid \\
\hline & $\mathrm{X} 1.3$ & 0,481 & 0,195 & Valid \\
\hline & X1.4 & 0,404 & 0,195 & Valid \\
\hline & X1.5 & 0,577 & 0,195 & Valid \\
\hline & X1.6 & 0,286 & 0,195 & Valid \\
\hline \multirow{5}{*}{$\begin{array}{l}\text { Peran nadzir } \\
\quad \text { (X2) }\end{array}$} & X2.1 & 0,574 & 0,195 & Valid \\
\hline & $X 2.2$ & 0,463 & 0,195 & Valid \\
\hline & X2.3 & 0,559 & 0,195 & Valid \\
\hline & X2.4 & 0,351 & 0,195 & Valid \\
\hline & X2.5 & 0,573 & 0,195 & Valid \\
\hline \multirow{5}{*}{$\begin{array}{l}\text { Tingkat kepercayaan muwakif } \\
\text { (Y) }\end{array}$} & Y1 & 0,536 & 0,195 & Valid \\
\hline & Y2 & 0,538 & 0,195 & Valid \\
\hline & Y3 & 0,648 & 0,195 & Valid \\
\hline & Y4 & 0,643 & 0,195 & Valid \\
\hline & Y5 & 0,524 & 0,195 & Valid \\
\hline
\end{tabular}

Sumber: Data diolah, 2019

Berdasarkan tabel 1 diatas, maka dapat diketahui bahwa $r$ tabel diperoleh sebesar 0,195. Sehingga dapat disimpulkan bahwa t hitung dari variabel Akuntabilitas pengelolaan wakaf tunai (X1), Peran nadzir (X2) dan Tingkat kepercayaan muwakif (Y) lebih besar dari t tabel, maka dikatakan valid. Artinya semua item pertanyaan mampu mengukur variabel akuntabilitas pengelolaan wakaf tunai, peran nadzir, dan tingkat kepercayaan muwakif.

\subsubsection{Uji Reliabilitas}

Uji Reliabilitas digunakan untuk mengukur suatu kuisioner yang yang merupakan indikator dari variabel. Pada dasarnya, suatu kuisioner dikatakan reliabel jika nilai Cronbach's Alpha > 0,50 (Delsie et al., 2018).

Berdasarkan tabel 2 dapat diketahui bahwa variabel akuntabilitas pengelolaan wakaf tunai (X1) sebesar 0,560 > 0,50, peran nadzir (X2) sebesar 0, $595>0,50$, dan tingkat kepercayaan muwakif sebesar 0,764 >0,50. Sehingga nilai Cronbach's Alpha tidak ada yang dibawah nilai kritis $>0,50$. Maka dapat disimpulkan bahwa variabel akuntabilitas pengelolaan wakaf tunai, peran nadzir dan tingkat kepercayaan muwakif yang digunakan dalam penelitian ini reliabel dan lolos untuk uji Reliabilitas. 
Tabel 2. Uji Reliabilitas

\begin{tabular}{|c|c|c|c|c|c|}
\hline \multicolumn{2}{|c|}{ Reliability Statistics } & \multicolumn{2}{|c|}{ Reliability Statistics } & \multicolumn{2}{|c|}{ Reliability Statistics } \\
\hline $\begin{array}{c}\text { Cronbach's } \\
\text { Alpha }\end{array}$ & $\begin{array}{l}\mathrm{N} \text { of } \\
\text { items }\end{array}$ & $\begin{array}{c}\text { Cronbach's } \\
\text { Alpha }\end{array}$ & $\begin{array}{l}\mathrm{N} \text { of } \\
\text { items }\end{array}$ & $\begin{array}{c}\text { Cronbach's } \\
\text { Alpha }\end{array}$ & $\begin{array}{c}\mathrm{N} \text { of } \\
\text { items }\end{array}$ \\
\hline ,560 & 6 &, 595 & 5 & ,764 & 5 \\
\hline \multicolumn{2}{|c|}{ Variabel } & \multicolumn{2}{|c|}{$\begin{array}{c}\text { Cronbach's } \\
\text { Alpha }\end{array}$} & Nilai Kritis & Keterangan \\
\hline \multicolumn{3}{|c|}{$\begin{array}{l}\text { Akuntabilitas pengelolaan wakaf } \\
\text { tunai (X1) }\end{array}$} & 0,560 & 0,50 & Reliabel \\
\hline \multicolumn{3}{|c|}{ Peran nadzir $(\mathrm{X} 2)$} & 0,595 & 0,50 & Reliabel \\
\hline \multicolumn{3}{|c|}{ Tingkat kepercayaan muwakif (Y) } & 0,764 & 0,50 & Reliabel \\
\hline
\end{tabular}

\subsection{UJI KETEPATAN MODEL}

\subsubsection{Uji F}

Uji F digunakan untuk mengetahui pengaruh secara simultan dari variabel independen terhadap variabel dependen. Jika, nilai signifikansinya kurang dari 0,05, maka variabel independen secara bersama-sama mempengaruhi variabel dependen. hasil Uji F dalam penelitian ini adalah sebagai berikut:

Tabel 3. Uji F

\begin{tabular}{|c|c|c|c|c|c|c|}
\hline & Model & $\begin{array}{l}\text { Sum of } \\
\text { Squares }\end{array}$ & Df & $\begin{array}{c}\text { Mean } \\
\text { Square }\end{array}$ & $\mathrm{F}$ & Sig. \\
\hline \multirow[t]{3}{*}{1} & Regression & 212,846 & 2 & 106,423 & 20,062 &, $000^{\mathrm{b}}$ \\
\hline & Residual & 514,544 & 97 & 5,305 & & \\
\hline & Total & 727,390 & 99 & & & \\
\hline $\begin{array}{l}\text { a. } \\
\text { b. }\end{array}$ & $\begin{array}{l}\text { Dependent Var } \\
\text { Predictors: (Co }\end{array}$ & M & & & & \\
\hline
\end{tabular}

Sumber: Data Primer yang diolah, 2019

Berdasarkan tabel 3 Hasil uji F dapat dilihat dari nilai F hitung, yaitu diperoleh hasil 20,062 dengan nilai signifikansi sebesar 0.000. Untuk mengetahui $\mathrm{F}$ table terlebih dahulu ditentukan derajat keabsahan (df1 dan df2). Dengan menggunakan signifikansi $\alpha=5 \%$, dimana df1 merupakan jumlah variable independen, df 2 (nilai dari model residual /n-k-1) atau sama dengan 100 dimana $\mathrm{n}$ adalah jumlah responden dan $\mathrm{k}$ adalah jumlah variable independen. Dalam F table diperoleh hasil 2,466 sehingga dapat disimpulkan bahwa nilai Fhitung > Ftabel $(20,262>2,466)$ dengan tingkat signifikansi $0.000<0.05$, sehingga dapat disimpulkan bahwa variabel akuntabilitas pengelolaan wakaf tunai dan peran nadzir secara simultan (bersama-sama) mempengaruhi Tingkat kepercayaan muwakif. 


\subsubsection{Koefisien Determinasi}

Koefisien determinasi digunakan untuk mengetahui presentase variabel independen secara bersama-sama dapat menjelaskan variabel dependen. Hasil pengujian koefisien determinasi terlihat pada table dibawah ini:

Tabel 4. Koefisien Determinasi

\begin{tabular}{|c|c|c|c|c|}
\hline \multicolumn{5}{|c|}{ Model Summary } \\
\hline Model & $\mathrm{R}$ & R Square & $\begin{array}{l}\text { Adjusted R } \\
\text { Square }\end{array}$ & $\begin{array}{l}\text { Std. Error of } \\
\text { the Estimate }\end{array}$ \\
\hline 1 &, $541^{\mathrm{a}}$ & ,293 &, 278 & 2,303 \\
\hline a. Predicto & ant), $\mathrm{PN}$, & WT & & \\
\hline
\end{tabular}

Berdasarkan tabel 4 Model Summary mempunyai nilai $R$ Square sebesar 0,278, sehingga dapat dikatakan bahwa akuntabilitas pengelolaan wakaf tunai dan peran nadzir berpengaruh sebesar 27,8\% atau 0,278 terhadap Tingkat kepercayaan muwakif. Sedangkan 0,722 atau 72,2\% lainnya dipengaruhi oleh variabel lain diluar model yang tidak diteliti.

Nilai $R$ Square yang kecil dikarenakan adanya faktor-faktor lain yang mempengaruhi variabel Tingkat kepercayaan muwakif. Karena pada dasarnya faktor-faktor lain seperti lokasi, sosialisasi, dan peran pemerintah juga turut mempengaruhi tingkat Tingkat kepercayaan muwakif yang melakukan wakaf di lembaga nadzir di Indonesia.

\subsubsection{Hasil Uji Regresi Linier Berganda}

Analisis regresi linier berganda digunakan untuk mengetahui pengaruh akuntabilitas pengelolaan wakaf tunai dan peran nadzir terhadap tingkat kepercayaan muwakif yang melakukan wakaf tunai di lembaga nadzir yang ada di Indonesia. Berdasarkan uji regresi linier berganda dapat diperoleh nilai regresi yang disajikan dalam tabel sebagai berikut:

Tabel 5 Uji Regresi Linier Berganda

\begin{tabular}{|c|c|c|c|c|c|c|}
\hline \multicolumn{7}{|c|}{ Coefficients $^{\mathrm{a}}$} \\
\hline & \multirow{2}{*}{ Model } & \multicolumn{2}{|c|}{ Coefficients } & \multirow{2}{*}{$\begin{array}{c}\begin{array}{c}\text { Standardized } \\
\text { Coefficients }\end{array} \\
\text { Beta }\end{array}$} & \multirow{2}{*}{$\mathrm{t}$} & \multirow{2}{*}{ Sig. } \\
\hline & & B & Std. Error & & & \\
\hline 1 & (Constant) & 7,166 & 1,925 & & 3,722 &, 000 \\
\hline & APWT & 347 & ,090 & ,375 & 3,871 &, 000 \\
\hline & $\mathrm{PN}$ & 270 &, 104 & 252 & 2,604 & ,011 \\
\hline
\end{tabular}

a. Dependent Variable: TKM

Sumber: Data Primer yang diolah, 2019

Berdasarkan tabel 5 di atas, maka dapat diperoleh hasil perhitungan regresi linier berganda sebagai berikut:

$\mathrm{Y}=7,166+0,347 \mathrm{X} 1+0,270 \mathrm{X} 2+\mathrm{e}$ 
Berdasarkan persamaan regresi yang telah disusun dapat diinterpretasikan sebagai berikut :

1. Nilai koefisien akuntabilitas pengelolaan wakaf tunai adalah sebesar 0,347. Hal ini berarti bahwa setiap kenaikan variabel Akuntabilitas wakaf tunai 1 satuan maka akan menaikkan variabel tingkat kepercayaan muwakif (Y) sebesar 0,347 satuan dengan asumsi bahwa variabel bebas yang lain dari model regresi adalah tetap.

2. Nilai koefisien peran nadzir adalah sebesar 0,270. Hal ini berarti bahwa setiap kenaikan variabel peran nadzir 1 satuan maka akan menaikkan variabel tingkat kepercayaan muwakif (Y) sebesar 0,270 satuan dengan asumsi bahwa variabel bebas yang lain dari model regresi adalah tetap.

Uji T menunjukkan seberapa jauh pengaruh suatu variabel independen secara individual dalam menerangkan variasi variabel dependen. Adapun prosedurnya adalah sebagai berikut:

Ho = Tidak terdapat pengaruh positif dari variabel bebas terhadap variabel terikat

$\mathrm{Ha}=$ Terdapat pengaruh positif dari variabel bebas terhadap variabel terikat.

Berdasarkan tabel 5 tersebut, pembuktian hipotesis dapat dijelaskan sebagai berikut:

1. Akuntabilitas pengelolaan wakaf tunai terhadap Tingkat kepercayaan muwakif.

Hasil Uji hipotesis variabel akuntabilitas pengelolaan wakaf tunai (X1) memiliki nilai t hitung sebesar 3,871 dengan tingkat signifikansi sebesar 0,000 , jika dibandingkan dengan $t$ tabel $(1,661)$ maka t hitung $>$ t tabel dan $\square$ $<0,05$. Hal ini menunjukan bahwa $\mathrm{H}_{1}$ ditolak dan $\mathrm{H} 1_{1}$ diterima.

Hasil Uji hipotesis variabel akuntabilitas pengelolaan wakaf tunai (X1) memiliki nilai t hitung sebesar 3,871 dengan tingkat signifikansi sebesar 0,000 , jika dibandingkan dengan $t$ tabel $(1,661)$ maka $t$ hitung $>t$ tabel dan $\square$ $<0,05$. Hal ini menunjukkan bahwa $\mathrm{H}_{1}$ diterima dan $\mathrm{H}_{1}$ ditolak, artinya Akuntabilitas pengelolaan wakaf tunai berpengaruh positif dan signifikan terhadap tingkat kepercayaan muwakif(Y).

Hasil ini menunjukan pelaksanaan akuntabilitas pada pengelolaan wakaf tunai di lembaga nadzir mampu meningkatkan kepercayaan muwakif. Hal ini sejalan dengan penelitian yang dilakukakan (Alzaina, 2019) yang menyatakan bahwa bahwa pemulihan tingkat kepercayaan bisa dilakukan dengan menerapkan standar tata kelola yang baik dan benar seperti penerapan akuntabilitas. Akuntabilitas merupakan bentuk pertanggungjawaban atas aktivitas organisasi dalam bentuk laporan oleh penerima amanah kepada pemberi amanah untuk mencapai tujuan organisasi. Dalam segi akuntansi, akuntabilitas adalah aktivitas untuk menghasilkan pengungkapan yang benar (Hamidi, 2013). Allah SWT berfirman dalam Al-Quran :

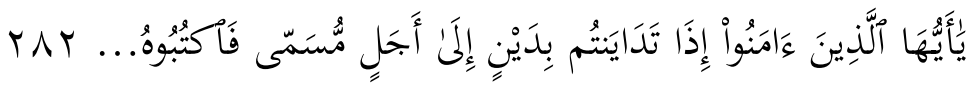


Artinya : "Hai orang-orang yang beriman, apabila kamu bermu'amalah tidak secara tunai untuk waktu yang ditentukan, hendaklah kamu menuliskannya..."(Q.S Al-Baqarah [2] : 282).

Dalam ayat ini Allah SWT menegaskan bahwasanya pencatatan dalam hal muamalah itu sangat penting, yang dimaksudkan dalam pencatatan adalah muwakif memberikan kepercayaan dan wewenang kepada lembaga nadzir dalam menghimpun dan mengelola sejumlah wakaf tunai. Oleh karena itu, tujuan dari pencatan adalah untuk tujuan keterbukaan, kebenaran, kepastian dan keadilan antara muwakif yang memberikan sejumlah uang dan nadzir yang mengelola wakaf uang tersebut.

Hasil penelitian ini menunjukan variabel yang berpengaruh positif dan signifikan dikarenakan akuntabilitas merupakan hal mendasar yang diperlukan untuk mencapai kinerja baik yang berkesinambungan. Organisasi atau lembaga yang baik harus menetapkan rincian tugas dan tanggung jawab masing-masing organ lembaga dan semua karyawan secara jelas dan selaras dengan visi, misi, sasaran usaha, dan strategi lembaga agar terpenuhinya prinsip akuntabilitas. Selain itu, penerapan akuntabilitas agar lembaga dikelola dengan sebaik mungkin maka lembaga harus memastikan adanya sistem pengendalian internal yang efektif dalam pengelolaan lembaganya.

Hipotesis pertama yang menyatakan bahwa akuntabilitas pengelolaan wakaf tunai berpengaruh positif terhadap tingkat kepercayaan muwakif juga mendukung teori stewarship yang diangkat dalam penelitian (Raharjo, 2007) yang menyatakan tingkat kepercayaan tertanam dalam hubungan kontraktual dapat diasumsikan untuk dibudidayakan. Di dalam stewardship theory mengidentifikasi tiga bentuk, dalam hubungan akuntabilitas (pertanggungjawaban) yaitu keberadaan Accountant, Accoutee, dan Accountor. Ketiga partisan tersebut saling berinteraksi dalam suatu jaringan. Accountant adalah pihak yang mengukur kinerja ekonomi, Accountee (steward) yaitu pihak yang bertanggungjawab, dan Accountor (principal) pertanggungjawaban diberikan atas apa yang telah dikerjakan dalam organisasi tersebut.

Pernyataan yang menjelaskan bahwa akuntabilitas pengelolaan wakaf tunai berpengaruh positif terhadap tingkat kepercayaan muwakif juga mendukung penelitian terdahulu yang dilakukan oleh (Ihsan et al., 2016) yang menyatakan sebagai institusi yang berhubungan dengan kepentingan orang banyak, masalah akuntabilitas adalah suatu keniscayaan dalam pengelolaan wakaf. Oleh karena itu penerapan akuntabilitas haruslah menjadi perhatian bagi semua lembaga nadzir agar mampu meningkatkan kepercayaan muwakif.

Dalam variabel akuntabilitas pengelolaan wakaf tunai yang terdiri dari 6 indikator berpengaruh positif terhadap tingkat kepercayaan muwakif, hal ini sejalan dengan apa yang telah dilakukan oleh (Hasrina et al., 2018) yang menyatakan bahwa akuntabilitas berpengaruh positif terhadap tingkat kepercayaan. Oleh karena itu, akuntabilitas pada lembaga-lembaga sosial khususnya lembaga nadzir harus selalu ditingkatkan supaya tingkat kepercayaan muwakif dan masyarakat umum lainnya semakin meningkat. 


\section{Peran nadzir terhadap Tingkat kepercayaan muwakif.}

Hasil Uji hipotesis variabel peran nadzir (X2) memiliki nilai t hitung sebesar 2,604 dengan tingkat signifikansi sebesar 0,011, jika dibandingkan dengan $\mathrm{t}$ tabel $(1,661)$ maka $t$ hitung $>t$ tabel dan $\square<0,05$. Hal ini menunjukan bahwa $\mathrm{H}_{2}$ ditolak dan $\mathrm{H}_{2}$ diterima.

Hasil Uji hipotesis variabel peran nadzir (X2) memiliki nilai t hitung sebesar 2,604 dengan tingkat signifikansi sebesar 0,011, jika dibandingkan dengan $\mathrm{t}$ tabel $(1,661)$ maka $\mathrm{t}$ hitung $>\mathrm{t}$ tabel dan $\square<0,05$. Hal ini menunjukkan bahwa $\mathrm{H}_{2}$ diterima dan $\mathrm{H}_{2}$ ditolak, artinya peran nadzir berpengaruh positif terhadap tingkat kepercayaan muwakif $(\mathrm{Y})$.

Hasil ini menunjukan peran nadzir pada pengelolaan wakaf tunai di lembaga nadzir mampu meningkatkan kepercayaan muwakif, hal ini sejalan dengan penelitian (Kasdi, 2014) yang menyatakan bahwa nadzir memiliki peran yang sangat penting dalam penghimpunan dan pengelolaan wakaf tunai, tentunya dalam hal untuk membuat kepercayaan muwakif meningkat peran nadzir harus senantiasa diperbaiki. Harus terdiri dari orang-orang yang baik, berahlak mulia, amanah, berpengalaman, dan memiliki administrasi yang baik agar nadzir mampu menjalankan setiap tugasnya dengan baik sehingga muwakif semakin percaya untuk menitipkan wakafnya.

Hasil penelitian ini menunjukan bahwa variabel peran nadzir (X2) berpengaruh positif dan signifikan terhadap tingkat kepercayaan muwakif (Y) hal ini mendukung penelitian (Tiswarni, 2014) yang menyatakan bahwa begitu pentingnya peran nadzir dalam mengelola dan mengoptimalkan wakaf tunai. Dalam hal ini tentunya nadzir dituntut untuk memiliki banyak kemampuan dalam mengoptimalkan wakaf tunai, karena kemunduran dan kemajuan wakaf dilihat dari performa nadzir yang profesional. Nadzir dituntut mampu untuk mengelola dengan cermat terkait dana wakaf tersebut dan mampu melihat investasi yang dapat memberikan keuntungan tinggi serta berada dalam bentuk investasi yang dibolehkan oleh syariat.

Hipotesis kedua yang menyatakan bahwa peran nadzir berpengaruh positif terhadap tingkat kepercayaan muwakif juga mendukung penelitian (Alzaina, 2019) yang menyatakan bahwa peran nadzir yang kreatif itu sangat diperlukan, karena apabila nadzir dapat lebih kreatif dan produktif, baik dalam hal pengelolaan maupun pengembangan dana wakaf yang telah muwakif amanahkan kepadanya sehingga mampu mengelola dengan lebih baik lagi bahkan wakaf mampu menaikan perekonomian masyarakat dan tentunya membuat kepercayaan muwakif semakin meningkat.

\section{SIMPULAN}

Berdasarkan analisis data dan pembahasan penelitian mengenai akuntabilitas pengelolaan wakaf tunai dan peran nadzir terhadap tingkat kepercayaan muwakif di Indonesia. Maka dapat disimpulkan sebagai berikut:

1. Akuntabilitas pengelolaan wakaf tunai (X1) berpengaruh positif dan signifikan terhadap tingkat kepercayaan muwakif (Y), dengan demikian 
untuk meningkatkan kepercayaan muwakif lembaga nadzir harus meningkatkan penyebarluasan informasi, kejujuran, tepat waktu, sesuai standar etika dan undang-undang, sasaran yang jelas, dan kemudahan akses informasi. sebagai institusi yang berhubungan dengan kepentingan orang banyak, masalah akuntabilitas adalah suatu keniscayaan dalam pengelolaan wakaf. Oleh karena itu penerapan akuntabilitas haruslah menjadi perhatian bagi semua lembaga nadzir agar mampu meningkatkan kepercayaan muwakif.

2. Peran nadzir (X2) berpengaruh positif dan signifikan terhadap tingkat kepercayaan muwakif (Y), tentunya dalam hal untuk membuat kepercayaan muwakif meningkat peran nadzir harus senantiasa diperbaiki dalam melakukan tugasnya. Dalam hal ini nadzir harus meningkatkan tanggungjawab penghimpunan dan pengelolaan wakaf tunai, efisiensi program dan anggaran, rasional antara rancangan anggaran dengan program yang akan dilaksanakan. Selain itu, nadzir harus terdiri dari orang-orang yang baik, berahlak mulia, amanah, berpengalaman, dan memiliki administrasi yang baik agar nadzir mampu menjalankan setiap tugasnya dengan baik sehingga muwakif semakin percaya untuk menitipkan wakafnya.

\section{DAFTAR PUSTAKA}

Alzaina, N. (2019). Urgensi Pemberdayaan Nadzir Dalam Pengelolaan Wakaf Uang Di Indonesia. Istismar: Jurnal Ekonomi Syariah, 1(1), $37-42$.

Bayinah, A. N. (2012). Transformasi Paradigma Masyarakat Terhadap Dasar Hukum Wakaf Produktif Di Indonesia. Jurnal Islamica, l(1).

Budiman, A. A. (2011). Akuntabilitas Lembaga Pengelola Wakaf. Walisongo: Jurnal Penelitian Sosial Keagamaan, 19(1), 75-102.

Dahlan, D. (2018). Penerapan Good Corporate Governance Pada Nazhir Tunai Yang Terdaftar Di Badan Wakaf Indonesia Studi Kasus Di Tabung Wakaf Indonesia Dan YPI Wakaf AL Azhar. Liquidity, 5(2), 95-105. https://doi.org/10.32546/lq.v5i2.50

Elrado H, M., Kumadji, S., \& Yulianto, E. (2014). Pengaruh Kualitas Pelayanan Terhadap Kepuasan, Kepercayaan Dan Loyalitas (Survei Pada Pelanggan Yang Menginap Di Jambuluwuk Batu Resort Kota Batu). Jurnal Administrasi Bisnis, 15(2), 1-9.

Fitri, R., \& Wilantoro, H. P. (2018). Analisis Prioritas Solusi Permasalahan Pengelolaan Wakaf Produktif ( Studi Kasus Kabupaten Banjarnegara. Jurnal Al-Muzara'ah, $6(1)$, 41-59. https://doi.org/10.29244/jam.6.1.41-59 
Hasrina, C. D., Yusri, Yusri, \& Agusti, D. R. (2018). Pengaruh Akuntabilitas dan Transparansi Lembaga Zakat Terhadap Tingkat Kepercayaan Muzakki Dalam Membayar Zakat Di Baitul Mal Kota Banda Aceh. Jurnal Humaniora: Jurnal Ilmu Sosial, Ekonomi Dan Hukum, 2(1), 19.

Ihsan, H., \& Ibrahim, S. M. (2011). WAQF accounting and management in Indonesian WAQF institutions: The cases of two WAQF foundations. Humanomics, 27(4). https://doi.org/10.1108/08288661111181305

Ihsan, H., Septriani, Y., \& Eliyanora. (2016). Akuntabilitas Pada Institusi Wakaf: Studi Kasus Pada Wakaf Daarut Tauhiid. In National Conference of Applied Sciences, Engineering. Business and Information Technology.

Jasfar, F. (2012). Teori dan Aplikasi Sembilan Kunci Keberhasilan Bisnis Jasa: Sumber Daya Manusia, Inovasi, Dan Kepuasan Pelanggan. Jakarta: Salemba empat.

Kasdi, A. (2014). Peran Nadzir Dalam Pengembangan Wakaf. Jurnal Zakat Dan Wakaf, 1(2).

Pitchay, A., \& Abd Jalil, M. I. (2016). The Constraints Of Malaysian Mutawalli In Developing In Developing Waqf Lands. In The Muktamar Waqf Iqlimi (Vol. III, pp. 1-9). https://doi.org/10.13140/RG.2.2.11520.84483

Santoso, N. H. (2017). Analisis Pengelolaan dan Pelaporan Keuangan Wakaf Tunai pada Tabung Wakaf Indonesia. IAIN Surakarta.

Sugara, A., \& Dewantara, R. Y. (2017). Analisis Kepercayaan dan Kepuasan Terhadap Penggunaan Sistem Transaksi Jual Beli Online (Studi Pada Konsumen “Z”). Jurnal Administrasi Bisnis, 52(1), 8-15.

Sugiyono, P. D. (2009). Metode penelitian kuantitatif kualitatif dam R\&D (cetakan ke. Bandung: ALFABETA cv.

Tiswarni. (2014). Peran Nazhir Dalam Pemberdayaan Wakaf (Tinjauan Terhadap Strategi Pemberdayaan Wakaf Badan Wakaf Alquran Dan Wakaf Center). Al-'Adalah, 12(2), 409-426.

Yaacob, H. (2013). Waqf History And Legislation In Malaysia: A Contemporary Perspective. Journal of Islamic and Human Advanced Research, 3(6), 387-402.

Yaacob, H., Petra, S., Sumardi, A., \& Nahar, H. S. (2015). Accountability through accounting and reporting lenses lessons from an awqaf institution in a Southeast Asia country. Humanomics, 31(3). https://doi.org/10.1108/H-07-2013-0049 
